into a semi-solid "pasty" condition. The quite violent movement of the autoclave fragmented the mass and the "pebbles" developed by mutual attrition. They remained slightly plastic for part of the agitated cooling period, during which they sagged on to one another and moulded themselves to the autoclave fittings.

I. M. KEEN

W. J. KING

BP Research Centre,

Sunbury-on-Thames,

Middlesex.

Received February 15, 1968.

1 Hay, R. L., Zeolites and Zeolitic Reactions in Sedimentary Rocks, 12, Spec. GSA Pap. No. 85 (New York, 1966).

${ }^{2}$ Ellis, A. J., Geochim. Cosmochim. Acta 19, 145 (1900).

UK patents 983,756 , published 17.2.65, and 992,872 , published 26.5.65.

- Sand, L. B., Mordenite Synthesis, paper presented at Molecular Sieve Conf. London (April 1967).

${ }^{5}$ How, H., Mineralogy of Nova Scotia (1869).

\section{Rates of Adsorption of Wetting Agents and Detergents}

ZetTLEMOyer et al. ${ }^{1}$ have recently reported considerable differences in the rates of adsorption of some isomeric surfactants, for example, sodium octyl $\alpha$-sulphopelargonate (I), a wetting agent, and sodium methyl $\alpha$-sulphopalmitate (II), a detergent, to 'Graphon'. Both 1 and II have the formula $R \mathrm{CH}\left(\mathrm{SO}_{8}^{-} \mathrm{Na}^{+}\right) \mathrm{COO} R^{\prime}$, but differ in the lengths of the chains $R$ and $R^{\prime}$. 'Type I compounds seem to adsorb threo-six times faster than typo II compounds. The explanations cited are a higher diffusion coefficient (D) or a faster sticking to the 'Graphon' surface for I (ref. 1).

I suggest that the important factor is the difference in the activities of the actual adsorbing species, the monomers and, perhaps, dimers, of I and II in the experiments performed. Double-chain salts such as $I$ have lower surface activity than their long-chain isomers, presumably because of greater difficulty of interfacial adsorption ${ }^{2}$. Indeed, at equilibrium, II adsorbs more to 'Graphon' than I (ref. 1). Similarly, the packing needed to produce large micelles is more difficult for molecules of type I and therefore micelle formation is energetically less favourable, and the critical micelle concentration (CMC) is higher. The CMC of I, for example, is $2.1 \times 10^{-3} \mathrm{M}$ (ref. 3), obtained by the somewhat uncertain dye-spectral change method 4 , while that of II is $4 \times 10^{-4} \mathrm{M}$ (ref. 3) as obtained by the dye method and $3.2 \times 10^{-4} \mathrm{M}$ from surface tensions ${ }^{5}$. Conductance measurements on many isomeric $R \mathrm{SO}_{4}^{-} \mathrm{Na}^{+}$salts, with $\mathrm{SO}^{-}$in different chain positions, show similar changes in the CMC (rof. 6). The differences expected between molecules of types I and II were discussed qualitatively by Hartley ${ }^{2}$ in 1941, who showed that type I compounds can produce very low interfacial tensions, a factor closely connected with their superior wetting power.

Zettlemoyer et al. ${ }^{1}$ used an initinl concentration of $5.8 \times 10^{-3} \mathrm{M}$, above the CMC for both I and II. Monomer activities change very little above the CMC and micelles are not surface active, so the "effective" activities of the adsorbing species for I and II are in the ratio of roughly 5 at $5.8 \times 10^{-3} \mathrm{M}$. The adsorption of I should therefore be about five times faster even if there are no differences in D and rates of "sticking".

Small but significant differences may, nevertheless, exist, particularly in D. The free energies of transfer from aqueous to hydrocarbon-like modia suggest that longchain compounds in water are not tightly coiled, and probably have extended random-coil type structures ${ }^{7}$. On such grounds, I should have a higher D than II because of greater compactness. Experimental evidence here, however, is conflicting. D can be estimated from conductance and transference data using the NernstHartley relationship ${ }^{8}$. The conductance data of Evans suggest an overall decrease in $\mathrm{D}$ as $\mathrm{SO}_{4}^{-}$is moved towards the middle of a chain. The data, unfortunately, show a wide scatter. On the other hand, Flockhart ${ }^{9}$ noted a higher conductance of $\mathrm{C}_{14} \mathrm{H}_{29} \mathrm{SO}_{4}^{-} \mathrm{Na}^{+}$as $\mathrm{SO}_{4}^{-}$was moved from position 1 to 2 and 4 . The calculated $D$ for the 4-sulphate is higher than that for the 1-sulphate by the significant factor of $\mathbf{1 \cdot 2 6}$.

Pasupati MuherJee

School of Pharmacy,

University of Wisconsin,

Madison.

Received December 29, 1987; revised February 12, 1968.

1 Zettlemoyer, A. C., Subba Rao, V. V., and Fix, R. J., Nuture, 216, 683 (1967); Chem. Eng. News, 52 (December 11, 1967).

" Hartley, G. S., Trans. Faraday Soc., 37, 130 (1941).

a Stirton, A. J., Bistline, jun., B. G., Weil, J. K., and Ault, W. C., J. Amer Oil Chem. Soc., 39, 55 (1962).

${ }^{4}$ Mukerjee, P., and Mysels, K. J., J. Amer. Chem. Soc., 77, 2937 (1955).

${ }^{s}$ Weil, J. K., and Stirton, A. J., J. Phys. Chem., 60, 899 (1956).

'Evans, H. C., J. Chem. Soc., 679 (1956).

Mukerjee, P., Advances in Colloid and Interface Science, 1, 241 (1967).

${ }^{8}$ Robinson, R. A., and Stokes, R. H., Electrolyte Solutions, second ed., $2 \times 5$ (Butterworths, 1959).

${ }^{9}$ Flockhart, B. D., J. Colloid Sci., 17, 305 (1962).

\section{Standard Potential of the Silver-Silver Bromide Electrode in Formamide}

As part of an investigation of the behaviour of electrolytes in formamide, we have now measured the molal standard e.m.f. of the cell $\mathrm{H}_{2} / \mathrm{HBr}(m) / \mathrm{AgBr} / \mathrm{Ag}$ in formamide at $25^{\circ} \mathrm{C}$.

Hydrogen and thermal-electrolytic silver-silver bromide electrodes were prepared according to the methods of Ives and Janz'. Only those silver--silver bromide electrodes with bias potentials below $150 \mu \mathrm{V}$ were used.

Pure formamide was prepared by repeated distillation, and had a freezing point of $2 \cdot 55^{\circ} \mathrm{C}$ and a specific conductance in the range $3-6 \times 10^{-8} \mathrm{ohm}^{-1} \mathrm{~cm}^{-1}$, which is in good agreement with values given in the literature ${ }^{2}$. Dry hydrogen bromide gas, generated by the action of bromine on tetrahydronaphthalene, was passed through formamide, in the presence of dry nitrogen. It was found possible to analyse the hydrogen bromides olutions by potentiometric titration against aqueous silver nitrate solution. The molal standard potential, $E^{0}$, was determ ined by extrapolating to zero molality the function $E^{\prime}$, given by

$$
E^{\prime}=E+2 \cdot 303 \times 2 R T / F(\log (m)-A \sqrt{ } m)
$$

where the symbols have their usual meanings. The value of the Debye-Hückel constant $A$ for formarnide ut $25^{\circ} \mathrm{C}$ is $0.3286(\mathrm{moles} / \mathrm{kg})^{-\frac{1}{2}}$. The values of $E^{\prime}$ are shown plotted against $m$ in Fig. 1 . The best straight line, fitted

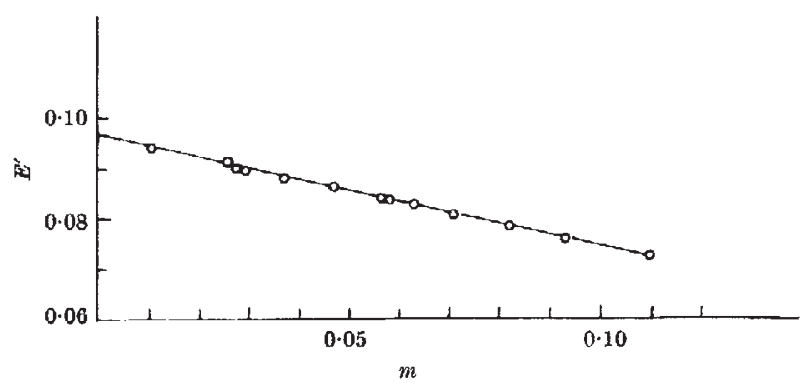

Fig. 1. Plot of $E^{\prime}$ against molality at $25^{\circ} \mathrm{C}$. 